\title{
Math approach of implementing ISO 27001
}

\author{
Liviu Adrian STOICA \\ Bucharest University of Economic Studies, Bucharest, Romania \\ liviu.stoica@csie.ase.ro \\ Robert Adrian CANDOI-SAVU \\ Bucharest University of Economic Studies, Bucharest, Romania \\ robertzvs@yahoo.com
}

\begin{abstract}
The objective of this paper work is to create a mathematical approach that can quantify the need of implementing the ISO 27001 in a company and the actual benefits of doing so. The scope is to identify the factors that determine vulnerabilities, what damages are caused by these factors, the risk and impact level of the factors. The approach is from the point of view of costs caused by implementing the standard compared with costs of potential damage by not implementing.
\end{abstract}

Keywords: Vulnerability, Analysis, Cost, Risk, Impact, ISO27001.

\section{Introduction}

Every type of business is at risk, both from the outside and from the inside. For a company to grow and have a sustainable business it has to protect itself from the possible threats that can appear and to ensure the competitiveness and achieve of proposed targets it must do the best to identify, evaluate and treat all of them. For each company the security and protection is a mandatory need for sustainability.

The critical factors for the successful implementation of security standards (ISO/IEC 17799:2005) consists from security policy, objectives, and activities that reflect business objectives; an approach and framework to implementing, maintaining, monitoring, and improving security that is consistent with the organizational culture; visible support and commitment from all levels of management; a good understanding of the information security requirements, risk assessment, and risk management; providing appropriate awareness, training, and education to all managers, employees, and other parties; establishing an effective security incident management process; implementation of a measurement system that is used to evaluate performance in security (Dima \& Vasilache, 2009).

Risk is an event that is waiting to happen. It is described as (ISO Guide 73:2009) in threats that exploit eventual system weaknesses, combination between the probability of an event and its consequences or a vulnerability triggered or exploited by a threat (NIST SP 800-61 Rev. 2 ). Risk analysis assumes a security risk identification process, determining the amplitude and also identifying the areas with a high degree of risk that need to be secured. Risk management is defined as the total system of identification, control, elimination or minimization method of the events that affect the system's resources. This includes risk analysis, the benefits cost analysis, mechanism selection, evaluating the adopted measures security, risk analysis in general.

Vulnerability means a flaw or weakness in system security procedures, design, implementations or internal controls that could be exercised (accidentally triggered or intentionally exploited) and result in a security breach or a violation of the system's security policy (NIST SP 800-61 Rev. 2). 


\section{Literature Review}

As (Jaya Sharma) ISO 27001 or formally known as ISO/IEC 27001:2005 is a set of specifications for managing risks to the security information that an organization holds. An ISMS constitutes of procedures and policies that includes all the legal, physical and technical aspects involved in an organization's information risk management process. The latest version of ISO is ISO 27001:2013 provides a set of standard requirements for Information Security Management System (ISMS). These standards help in establishing, implementing, operating, monitoring, maintaining as well as improving ISMS. Overall, ISO 27001 helps organization in:

- Protecting client and employee information,

- Effective management of risks to information security

- Compliance management with other regulations like GDPR, SOX etc.

- Safeguarding sensitive as well as confidential data and information

- Identifying safety issues and minimizing risk exposure

- Make products compatible with each other

- ISO 27001 can be implemented in any of the sectors where confidentiality of data is crucial. For example, Banking, IT sector, Finance, Healthcare etc.

- Exploring new markets for business expansion

- Complying legal requirements since laws, regulation and contractual requirements can be fulfilled by implementing ISO 27001.

As (Barnaby Lewis 2019) says, the attraction of cybercrime to criminal hackers is obvious: tangled webs of interactions, relatively low penalties, disjointed approaches on money laundering and potentially massive payouts. The key is preparation and seeing vulnerabilities, and resilience, in terms of interactions with overall management systems, and that's where information security management systems (ISMS) standard ISO/IEC 27001 comes in. This is the flagship of the ISO/IEC 27000 family of standards, which was first published more than 20 years ago. Developed by ISO/IEC JTC 1, the joint technical committee of ISO and the International Electrotechnical Commission (IEC) created to provide a point of formal standardization in information technology, it has been constantly updated and expanded to include more than 40 International Standards covering everything from the creation of a shared vocabulary (ISO/IEC 27000), risk management (ISO/IEC 27005), cloud security (ISO/IEC 27017 and ISO/IEC 27018) to the forensic techniques used to analyze digital evidence and investigate incidents (ISO/IEC 27042 and ISO/IEC 27043 respectively). These standards are not only about helping to manage information security but will also help to identify and bring criminals to justice. For example, ISO/IEC 27043 offers guidelines that describe processes and principles applicable to various kinds of investigations, including, but not limited to, unauthorized access, data corruption, system crashes, or corporate breaches of information security, as well as any other digital investigation.

Based on (Heru Susanto, Mohammad Nabil Almunawar, Yong Chee Tuan - 2012) since information security has a very important role in supporting the activities of the organization, we need a standard as benchmark which regulates governance over information security. There are several standards for IT Governance which leads to information security such as PRINCE2, OPM3, CMMI, P-CMM, PMMM, ISO27001, BS7799, PCIDSS, COSO, SOA, ITIL and COBIT. However, some of these standards are not well adopted by the organizations, with a variety of reasons. The big five are ISO27001, BS 7799, PCIDSS, ITIL and COBIT. The comparative study conducted to determine their respective strengths, focus, main components and their level of 
adoption, concluded that ISO 27011 is most widely used standard in the world in information security area.

In (Carol Hsu, Tawei Wang, Ang Lu (2016)) the extensive organizational dependence on information technology (IT), along with worsening impact of information security incidents, has made information security one of the top management concerns. The ISO 27001 standard provides guidance to a sound information security management system (ISMS). However, implementation and accreditation costs can also be considerable. In this study, they explored whether the certification can benefit organizations by signaling the management's attitude toward security management and the appropriateness of ISMS implementation. They investigated firm performance after the ISO 27001 certification with samples from the United States and selected European countries. Different from expectation, they found no evidence that ISO 27001 certification brought benefits to the certified firm in terms of return-on-assets and stock market performance. They attributed the results to the nature of ISO 27001 that a good information security management would be seen as an obligation, instead of a competitive advantage.

\section{Defining the risk model}

The risk assessment starts with defining the rules, based on ISO27001 risk assessment methodology, to ensure that the whole organization apply same rules it the same way. After defining the rules, it starts identifying the potential problems that could arise and evaluate them to decide which can be accepted and which need to be treated. Some threats are with low and insignificant impact and is economically better to just accept them as they are and to adapt instead invest to totally remove them. This means analyze, identify and evaluate the risks. The treating of risks must be done with minimal investment and maximum protection.

All the steps in managing and preparing the risk approach must be documented step by step. This is used for internal revision and for auditing purposes too.

To determine the risk level of a factor $f$ on the company system, the following formula is used:

$$
\mathrm{CSRL}_{\mathrm{f}}=\mathrm{I}_{\mathrm{f}} * \mathrm{P}_{\mathrm{f}} \text {, (Table 1) where: }
$$

- $\mathrm{CSRL}_{\mathrm{f}}=$ Company System Risk Level of factor $\mathrm{f}$

- $\mathrm{f}=$ factor

- $\mathrm{I}_{\mathrm{f}}=$ the impact produced by factor $\mathrm{f}$

- $\mathrm{P}_{\mathrm{f}}=$ probability of event for factor $\mathrm{f}$

Table 1. Company System Risk Level

\begin{tabular}{|l|c|c|c|c|c|}
\hline \multicolumn{1}{|c|}{ Impact/Probability (IP) } & Rare (1) & Likely (2) & Periodicals (3) & Regular (4) & Continuous (5) \\
\hline Insignificant (1) & 1 & 2 & 3 & 4 & 5 \\
\hline Poor (2) & 2 & 4 & 6 & 8 & 10 \\
\hline Medium (3) & 3 & 6 & 9 & 12 & 15 \\
\hline Important (4) & 4 & 8 & 12 & 16 & 20 \\
\hline Catastrophic (5) & 5 & 10 & 15 & 20 & 25 \\
\hline
\end{tabular}

Source ISO Guide 73:2009 adapted by authors' own research

As example for a better understanding of the need to implement the risk management and evaluate the threats are given the following examples: 
a) We have as asset a paper document. We can identify as a factor the fire. The vulnerabilities that can be identified are: document is not stored in a fire-proof cabinet and there is no backup of the document that reflect in potential loss of availability of the document. As other example of factor it can be unauthorized access with the vulnerability that the document is not locked in a secure place which can lead to potential loss of confidentiality;

PICBE | 524

Observation: In this example to protect the document based on the two threats identified is needed that the document to be stored on a fireproof locked safe, with the mention that the document or documents used are containing sensitive data that is evaluated in case of loss/lost more than the investment in the protection safe locker.

b) We have as asset a computer. As factor it can be a disk failure with the vulnerability of no backup which leads to loss of data availability or performance of work. Other factor can be unauthorized access which can have as vulnerability that the access was given to too many employees or is not properly implemented a control access scheme and all this can lead to loss of confidentiality, integrity or availability of the information stored on the asset.

Observation: in this example, depending on the sensitiveness of data or the actual use of computer, that can be as programming-developing one, the situations of protections that can be move all work in cloud computing at a less costs then back-up on external databases hosted in same company and using of firewalls it is decided based on the actual benefits of data protection not of costs to protect.

The implementation of protection and security is not based just on costs versus protection, considering the lowest costs to protect from low to high as order, it is based on costs - stability where costs and stability are directly proportional.

In this case we need calculate a sum of possible threats and probabilities for each asset. That means the total risk level of an asset a is calculated using formula:

$$
\mathrm{TRL}_{\mathrm{a}}=\sum_{1}^{n} \operatorname{CSRL}_{f} * e, \text { where }:
$$

- $\mathrm{TRL}_{\mathrm{a}}=$ Total risk level of an asset a

- $\mathrm{a}=$ asset

- $\mathrm{n}=$ total number of identified factors for each type of asset

- $\quad \mathrm{e}=$ error adjustment in case of unidentified factors or vulnerabilities

The error can be approximate by including number of potential factors by percentage as it follows: if the asset have between 1 and 5 factors the error will be 1.8, if it have between 6 and 10 the error is 1.6, between 11 and 20 error is 1.4 , between 21 and 30 the error is 1.2 and from 31 and up the error is 1.1 going down to as close as 1 . The error approximation can be adjusted on a larger scale according to the complexity and number of assets analyzed. This approach ensures a more stability for the risk level in case of the unidentified vulnerabilities and same time enforce the responsible of procedure management to take into consideration as many factors as it can exist and assure a continuous development and improvement of the procedures.

To improve the evaluation for obtaining an even more accurate approach we need to include the Impact level of asset which is given by the correlation between the value of the asset that can be lost and impact on business of losing the asset itself, as it is expressed in Table 2. The impact is directly referring as a consequence of materially loss or damage of the asset itself or 
any directly or indirectly loses that comes from this incident. The correlation between the impact and percentage is directly proportional.

Table 2. Impact Level of Assessment

\begin{tabular}{|c|c|c|c|}
\hline Value & Consequences & Percent & $\mathrm{IL}_{\mathrm{a}}$ \\
\hline minimal & The loose of the asset do not have implications on business & $1-10$ & $1-5$ \\
\hline low & The business can be affected insignificant & $11-25$ & $6-15$ \\
\hline medium & The business is affected until replacement & $26-50$ & $16-30$ \\
\hline high & The business if affected even after replacement of asset but can recover & $51-80$ & $31-50$ \\
\hline total & Business is in danger & $81-100$ & $51-100$ \\
\hline
\end{tabular}

PICBE | 525

Source: Authors' own research

To calculate the loss caused by risk of an asset based on all factors and vulnerabilities identified and the value and business percentage of affection is using the formula:

$$
\operatorname{Risk}_{a}=\mathrm{TRL}_{a} * \mathrm{IL}_{a}=\sum_{1}^{n} C S R L_{f} * e * I L_{a}
$$

Based on the new approach we can evaluate the risk of an asset computer with threats disk failure $\left(f_{1}\right)$ and unauthorized access $\left(f_{2}\right)$ as it follows:

$$
\text { Risk }_{\text {computer }}=\mathrm{TRL}_{\text {computer }} * \mathrm{IL}_{\text {computer }}=\sum_{1}^{2} C S R L_{f} * e * I L_{\text {computer }}
$$

Risk $_{\text {computer }}=\left(\mathrm{I}_{1} * \mathrm{P}_{1}+\mathrm{I}_{2} * \mathrm{P}_{2}\right) * \mathrm{e} * \mathrm{IL}_{\text {computer }}=(3 * 1+4 * 3) * 1.8 * 3=81 \mathrm{pm}($ where $\mathrm{pm}=$ points of measurement)

To calculate the total risk of the business, including all types of assets that can be identified as equipment, employees is used the formula:

$$
\mathrm{TRB}=\sum_{1}^{q} \text { Risk }_{a}
$$

Based on the TRB it must be created a set of rules and regulations that, by implementing it reduce the TRB. This can be achieved by definition of new rules, where rules are documented through plans, policies, procedures, instructions, implementation of new technology as backup systems, disaster recovery locations for alternative data centers, etc. and even change of the organizational structure that imply in some cases, the need to introduce a new job function, or change the responsibilities of an existing position.

To increase the implementing of the most efficient rules the management should be involving specialists in the related areas as IT specialist for network security, HR for recruiting and verifying the employment requirements and conditions and others.

All the risks determined can be evaluated in acceptable or mandatory to fix. Based on this they can be included in the total evaluation or ignored. The complexity is mandatory on sensitive business and avoidable on low and normal business.

\section{Mathematical definition}

To can elaborate the implementation of ISO27001 we need to set the main security categories which contains a control objective stating what is to be achieved and one or more controls that can be applied to achieve the control objective as in (ISO/IEC 17799:2005); The control is 
structured in three steps as control, which defines the specific control statement to satisfy the control objective, the implementation guidance which provides more detailed information to support the implementation of the control and meeting the control objective and other information that provides further information that may need to be considered, for example legal considerations and references to other standards.

For a stable analyze we define the evaluation for each subcategory of rules that will help

PICBE | 526 define the risks assessments and threat levels, as it is shown in Table 3.

Table 3. Points of evaluation

\begin{tabular}{|c|c|c|}
\hline Category & Subcategory & Evaluation \\
\hline \multirow[t]{2}{*}{$\begin{array}{l}\text { Information security } \\
\text { policy }\end{array}$} & Information security policy & $\begin{array}{l}\text { Based on number of different politics that are used } \\
\text { and mode of implement and complexity }\end{array}$ \\
\hline & $\begin{array}{l}\text { Review of the information } \\
\text { security policy }\end{array}$ & $\begin{array}{l}\text { Frequency of revision, number of politics added or } \\
\text { removed }\end{array}$ \\
\hline \multirow{4}{*}{$\begin{array}{l}\text { Organization of } \\
\text { information security - } \\
\text { Internal organization }\end{array}$} & $\begin{array}{l}\text { Roles and responsibilities } \\
\text { regarding information security }\end{array}$ & $\begin{array}{l}\text { Based on number of roles, and classification of each } \\
\text { role on scale of importance }\end{array}$ \\
\hline & Separation of tasks & Scale of importance for each task, subdivision of roles \\
\hline & $\begin{array}{l}\text { Contact with the authorities / } \\
\text { interest groups }\end{array}$ & $\begin{array}{l}\text { Frequency of contact, number of authorities or } \\
\text { interest groups }\end{array}$ \\
\hline & Security of information & Classify the access to information on security levels \\
\hline \multirow{4}{*}{$\begin{array}{l}\text { Human } \\
\text { security }\end{array}$} & Verification & Scale of verification check before employment \\
\hline & $\begin{array}{l}\text { Employment requirements and } \\
\text { conditions }\end{array}$ & $\begin{array}{l}\text { Scale of importance of position and access in } \\
\text { company }\end{array}$ \\
\hline & Training & Number of courses, costs and benefits \\
\hline & Disciplinary process & Penalties for employees \\
\hline \multirow[t]{3}{*}{ Resources } & Resource inventory & Number and value of resources \\
\hline & Utilization of assets & Procedures and training for utilization \\
\hline & Protection of assets & Procedure to protect the assets \\
\hline \multirow{2}{*}{$\begin{array}{l}\text { Classification of } \\
\text { information }\end{array}$} & Classification of information & Levels of security \\
\hline & Manipulation of information & Vulnerabilities \\
\hline
\end{tabular}

Source: ISO/IEC 27002:2013 adapted by authors' own research

\section{Mathematical approach}

To develop an evaluation formula for implementation, we take into account the following elements:

$>$ defining the types of risks;

$>$ training of employees to improve the quality of work and avoid the possible losses of assets by diminishing the vulnerabilities and also in the scope of efficiency the production;

purchase of equipment for research, testing and protection;

$>$ investments in security;

$>$ laws and regulations;

$>$ complexity of security policy;

$>$ complexity of roles in company;

To calculate the evaluation for implementation EFI, the following formula is used:

$$
E F I=\sum_{i=1}^{n} I S P_{i} * R w+O I S+H R S+T R B+C I+A D C+\sum I M P C_{z}, \text { where }:
$$


- $\mathrm{ISP}_{\mathrm{i}}=$ evaluation of information security policy $\mathrm{i}$

- $\mathrm{n}=$ number of policies defined

$$
\operatorname{ISP}_{\mathrm{i}}=\mathrm{C}_{\mathrm{i}} * \mathrm{I}_{\mathrm{i}} * \mathrm{~A}_{\mathrm{i}} \text {, where: }
$$

- $\mathrm{C}_{\mathrm{i}}=$ defines the complexity of the policy, calculated based on a scale from 1 to 10

- $\mathrm{I}_{\mathrm{i}}=$ represent the impact of the policy in the organization, calculated in percent

PICBE $\mid 527$

- $\mathrm{A}_{\mathrm{i}}=$ defines the easiness to apply the policy, defined on a scale from 1 to 5

- $\mathrm{Rw}=$ defines the frequency of reviews on defined policies, and is calculated as number of reviews per year divided by ten

- $\mathrm{OIS}=$ evaluation of structuring the information security

$$
\text { OIS }=\left(\sum_{j=1}^{p} R_{j} * C s_{j} * S_{j}+T S K\right) * F q+\sum_{k=1}^{q} L S_{k}, \text { where: }
$$

- $R_{j}=$ role $j$ defined in the company

- $\quad \mathrm{Cs}_{\mathrm{j}}=$ complexity of role, calculated on a scale from 1 to 5

- $\mathrm{S}_{\mathrm{j}}=$ scale of importance of role in the company, defined on a scale from 1 to 5

- $\quad$ TSK $=$ defines the separation of tasks and is evaluated based on task importance and number of tasks $=\sum T_{I}$, where importance is based on a scale from 1 to 100

- $\mathrm{Fq}=$ defines the frequency of contact the authorities or other interested parties in security of the company and is calculated as number of interactions per year or number of parties contacted divided by ten $=(\mathrm{Nit} * \mathrm{Nprt}) / 10$

- $\quad \mathrm{LS}_{\mathrm{k}}=$ evaluation of levels of security for access

$$
L S_{k}=\sum_{k=1}^{q} \operatorname{Sen}_{k} * \operatorname{Imp}_{k}, \text { where }:
$$

- $\quad$ Sen $_{k}=$ Sensitivity of information, from 1 to 100

- $\quad \operatorname{Imp}_{\mathrm{k}}=$ Level of access required

- $\quad \mathrm{HRS}=$ defines the evaluation of employees

$$
H R S=\sum_{e=1}^{z} \operatorname{Ver}_{e} * \operatorname{Req}_{e} * \operatorname{Pos}_{e}-\text { Pen }_{e}+\text { CTR, where }
$$

- $\quad \operatorname{Ver}_{\mathrm{e}}=$ verification requirement for employee on a scale from 1 to 10

- $\mathrm{Req}_{\mathrm{e}}=$ knowledge requirement for employee on a scale from 1 to 5

- $\operatorname{Pos}_{\mathrm{e}}=$ defines the position in company where 10 is CEO and 1 lowest position, an employee that can be changed any time without affecting anything

- $\quad \mathrm{Pen}_{\mathrm{e}}=$ penalties for employee on a scale from 1 to 50

- $\quad \mathrm{CTR}=$ training costs for employees on a scale from 1 to 50

- $\mathrm{TRB}=$ evaluation of assets, calculated as total risk of business

$$
\mathrm{TRB}=\sum_{1}^{q} \text { Risk }_{\text {asset }}
$$

- $\quad \mathrm{CI}=$ evaluation of sensitive data, calculated using same formula as evaluating the assets, just using the rules of definition for information itself 


$$
\mathrm{CI}=\sum_{1}^{q} \text { Risk }_{\text {information }}
$$

- $\mathrm{ADC}=$ adjacent evaluations

- $\quad \mathrm{RC}=$ research cost

$$
\mathrm{ADC}=\mathrm{RC}+\mathrm{IC}+\mathrm{BA}+\mathrm{LW}, \text { where: }
$$

- $\quad \mathrm{IC}=$ implementing costs

- $\quad \mathrm{BA}=$ business analyze costs

- $\quad \mathrm{LW}=$ laws costs

- $\quad \mathrm{IMPC}_{\mathrm{z}}=$ improvement costs and is calculated by the cost of location fee, location statistical analyze of business development of implementation $\mathrm{z}$

- $\mathrm{CF}_{\mathrm{z}}=$ cost of location fee

$\mathrm{IMPC}_{\mathrm{z}}=\mathrm{CF}_{\mathrm{z}}+\mathrm{CBD}_{\mathrm{z}},+\mathrm{RC}_{\mathrm{z}}+\mathrm{RA}_{\mathrm{z}}$, where:

- $\mathrm{CBD}_{\mathrm{z}}=$ cost of business analyze

- $\quad \mathrm{RC}_{\mathrm{z}}=$ research costs

- $\quad \mathrm{RA}_{\mathrm{z}}=$ analyze costs

- $\quad$ SL $=$ study cost for location

$$
\mathrm{CF}=\mathrm{SL}+\mathrm{PL} \text {, where: }
$$

- $\quad \mathrm{PL}=$ the costs of preparing the location according to the business and laws standards

$$
\mathrm{RC}_{\mathrm{z}}=\mathrm{CEch}+\mathrm{CP}+\mathrm{CA} \text {, where }
$$

- $\quad \mathrm{CEch}=$ equipment cost and is calculated by summing up the costs of all equipment that is divided into three major groups: research equipment, testing equipment and protective equipment.

- $\quad \mathrm{CP}=$ cost of losses obtained by impact on loosing information

- $\mathrm{CA}=$ cost of insurance and is calculated by summing the insurance costs for environment, buildings, land, equipment, health.

$$
\mathrm{RA}=\mathrm{RCA}+\mathrm{RIA} \text {, where: }
$$

- $\quad \mathrm{RCA}=$ risk asset analyze

- $\quad$ RIA = risk investment analyze

The final and detailed equation used is:

$$
\begin{array}{rl}
E F I=\sum_{i=1}^{n} C_{i} & * I_{i} * A_{i} * R w+\left(\sum_{j=1}^{p} R_{j} * C s_{j} * S_{j}+\sum T\right) * \frac{N i t * N p r t}{10}+\sum_{k=1}^{q} \text { Sen }_{k} * \operatorname{Imp}_{k} \\
& +\sum_{e=1}^{z} \operatorname{Ver}_{e} * \operatorname{Req}_{e} * \operatorname{Pos}_{e}-P_{e} n_{e}+C T R+\sum_{1}^{q} \text { Risk }_{\text {asset }}+\sum_{1}^{q} \text { Risk }_{\text {information }} \\
& +\mathrm{RC}+\mathrm{IC}+\mathrm{BA}+\mathrm{LW}+\sum \mathrm{SL}_{z}+\mathrm{PL}_{z}+\mathrm{CBDz},+\mathrm{RCz}+\mathrm{RAz}
\end{array}
$$

The evaluation is calculated in pm (points of measurement) and it should be as low as possible for an efficient system.

The formula proposed for the evaluation can be used as a software application, that include as the input all the assets, the corresponding identified threats and the tables of evaluation for each asset. All the threats tables and assets are updated in real time based on the fluctuation of elements in the business. The reports and results of the analyze will help improve the 
implementation of the standards and increase the security of the company and a better stability of development.

\section{Conclusion}

Considering the need of each business to be protected and to can grow sustainable, it is mandatory to implement all standards of security to ensure the highest protection and same time to lower the costs as much as possible. This method of evaluation the implementation of the ISO27001 it helps the company to settle the internal rules and regulations, to identify potential threats, to can manage the assets and information and to maintain trained and informed employees. Used as software application for analyze it helps the management of the company to cam make a proper financial planning, to have a risk management of each aspect of the business, to know in real time most of the threats they or the business can face, reduce the costs that are caused by malfunctions or errors.

All the operations during the evaluation process must be carefully revised and based on the complexity and volume of company to be extended or lowered as much as it can be on each branch. On a new company or a low profit company the definitions must be kept as minimum possible, with minimum rules and regulations, compared with a corporation where each detail of each factor involved in the business must be analyzed, documented and included in the evaluation process.

\section{References}

Alina Mihaela Dima, Simona Vasilache (2009). ANN model for corporate credit risk assessment, 2009 International Association of Computer Science and Information Technology Spring Conference (IACSIT-SC2009), International Conference on Information and Financial Engineering (ICIFE2009), Singapore, 17-19 April 2009, pp. 94-98.

Paul Cichonski, Thomas Millar, Tim Grance, Karen Scarfone (2012). Computer Security Incident Handling Guide [NIST SP 800-61 Rev. 2], Retrieved from https://nvlpubs.nist.gov/nistpubs/SpecialPublications/NIST.SP.800-61r2.pdf

Calder Alan, Watkins Steve G. (2009), Information Security Risk Management for ISO27001 / ISO27002, IT Governance Publishing, ISBN 978-1-84928-044-0

Heru Susanto, Mohammad Nabil Almunawar, Yong Chee Tuan (2012), Information Security Challenge and Breaches: Novelty Approach on Measuring ISO 27001 Readiness Level, International Journal of Engineering and Technology Volume 2 No. 1

By Barnaby Lewis (2019), How to tackle today's IT security risks, retrieved from https://www.iso.org/news/ref2360.html

Carol Hsu, Tawei Wang, Ang Lu (2016), The Impact of ISO 27001 Certification on Firm Performance, Koloa, HI, USA, ISBN 978-0-7695-5670-3

Eleni Philippoua, Sylvain Frey, Awais Rashid (2020), Contextualising and aligning security metrics and business objectives: A GQM-based methodology, Computers \& Security, Volume 88

Jaya Sharma, Why do organizations need ISO 27001?, Retrieved from https://kratikal.com/blog

ISO. (2017). ISO Survey. Retrieved from www.iso.org

ISO27000. (2018). Information technology. Security techniques. Information security management systems. Overview and vocabulary. Retrieved from www.iso.org 
ISO27001. (2013). Information technology. Security techniques. Information security management systems. Requirements. Retrieved from www.iso.org

ISO27002. (2013). Information technology. Security techniques. Code of practice for information security controls. Retrieved from www.iso.org

ISO27005. (2016). Information technology. Security techniques. Information security risk management. Retrieved from www.iso.org

PICBE | 530

LukeBriner (2018), Making information security easier, Computer Fraud \& Security, Issue 4, 1014

\section{Acknowledgment}

This paper was co-financed from the Human Capital Operational Program 2014-2020, project number POCU / 380/6/13/125245 no. 36482 / 23.05.2019 "Excellence in interdisciplinary PhD and post-PhD research, career alternatives through entrepreneurial initiative (EXCIA)", coordinator The Bucharest University of Economic Studies". 